EDITOR

Roger Jones, DM, FRCP, FRCGP, FMedSci London

DEPUTY EDITOR

Alec Logan, FRCGP

Motherwell

JOURNAL MANAGER

Catharine Hull

SENIOR ASSISTANT EDITOR

Erika Niesner

ASSISTANT EDITOR

Moira Davies-Cinar

EDITORIAL ASSISTANT

Tania Marszalek

ADVERTISING EXECUTIVE

Brenda Laurent

EDITORIAL BOARD

Richard Baker, MD, FRCGP

Leicester

Stephen Barclay, MD, FRCGP, DRCOG

Cambridge

Chris Butler, MD, MRCGP

Cardiff

Kath Checkland, PhD, MRCGP

Manchester

Mark Gabbay, MD, FRCGP

Liverpool

Clare Gerada, MBE, FRCGP, MRCPsych

London

Murray Lough, MD, FRCGP

Glasgow

David Mant, MD, FRCGP, FMedSci

Oxford

Tim Peters, MSc, PhD, CStat, FFPH

Bristol

Chris Salisbury, MD, FRCGP

Bristol

John Sandars, MSc, MD, FRCGP, MRCP

Leeds

Mark Shapley, FRCGP, DCH, DRCOG

Newcastle-under-Lyme

Niroshan Siriwardena, MMedSci, PhD,

FRCGP

Lincoln

Theo Verheij, MD, PhD, MRCGP

Utrecht, The Netherlands

Sue Wilson, BA, PhD, PGA

Birmingham

2009 impact factor: 2.442

EDITORIAL OFFICE

1 Bow Churchyard, London, EC4M 9DQ

(Tel: 0203188 7400, Fax: 0203188 7400).

E-mail: journal@rcgp.org.uk

http://www.rcgp.org.uk/bjgp

PUBLISHED BY

The Royal College of General Practitioners,

1 Bow Churchyard, London, EC4M 9DQ.

Registered charity number 223106. The BJGP is published by the RCGP, but has complete

editorial independence. Opinions expressed in the BJGP should not be taken to represent the policy of the RCGP unless this is specifically stated.

No endorsement of any advertisement is implied or intended by the RCGP.

PRINTED IN GREAT BRITAIN BY

HPM Limited, Prime House, Park 2000, Heighington

Lane Business Park,

Newton Aycliffe, Co. Durham DL5 6AR.

Printed on $100 \%$ recycled paper

ISSN 0960-1643 (Print)

ISSN 1478-5242 (Online)

\title{
October Focus
}

\section{ACUTE AND CHRONIC ILLNESS}

There is plenty of controversy in this month's BJGP. Getting people on longterm sickness benefit back to work has become an increasingly pressing policy goal for the UK government, who will not have been encouraged by the recent study by Whittaker and colleagues which implies that most patients on long-term benefits really are unfit to work. ${ }^{1}$ The complex interplay between the advocacy role of GPs, their societal responsibility for equity and probity, the use of the new 'fit note' system, and the place of special training for GPs are further explored in Jill Morrison's editorial (page 715) and in the qualitative study from Manchester by Annemarie Money and colleagues (page 721). Without more formal occupational health training it seems invidious to continue to ask GPs to play an extended role as some kind of proxy for their patients' employers, yet the chances of this additional training being provided or even welcomed are slim. It may be time for a complete re-evaluation of the underresearched and conflictual role of GPs in determining fitness to work.

The provision of out-of-hours and emergency primary care has been headline news for several months. The study from Boeke and colleagues in Amsterdam (page 729) reminds us of the earlier work in south London by Jeremy Dale's group, ${ }^{2}$ which demonstrated the value of involving trained GPs in the care of patients attending accident and emergency departments - fewer unnecessary investigations, fewer delays in management, and greater patient satisfaction. General practice, rather than internal medicine, training equips doctors to deal efficiently and effectively with acute illness in these settings. We need to ensure, with particular reference to the problems being caused by the European Working Time Directive, that our trainees in general practice continue to experience acute medicine out of hours.

Acute medicine is the focus of many of the research papers this month. Melvyn Jones (page 735) warns us that patients with atypical presentations of ischaemic heart disease may not get the right investigations at the right time and the paper on deep vein thrombosis from the Netherlands (page 742) offers a clinical decision rule which combines diagnostic accuracy with a reduction in referrals for ultrasonography. The power of the General Practice Research Database to provide clinically valuable information when it is asked the right questions is demonstrated in two studies from Brighton. Nicholson and co-workers provide useful and salutary information on the primary care management of pelvic inflammatory disease (page 756) and of epididymoorchitis (page 763) which, as well as highlighting current questions about management, point to clear further research questions for the future. McNally and colleagues' systematic review on predicting the severity of pneumonia (page 770) sounds a note of caution about the use of the CRB-65 score, based on the presence of confusion, respiratory rate, blood pressure, and age over 65 years, because it appears to over-predict mortality and needs further validation studies before finding a routine place in clinical assessment of pneumonia in primary care. Pneumonia may be an unexpectedly common unwanted effect of the prescription of antipsychotic drugs in older people according to the cohort study from Sweden by Kristina Star and colleagues (page 749), which adds to the evidence from hospital-based research pointing towards a causal relationship.

The research and educational interactions between the hospital and primary care sectors in the newly-created Academic Health Sciences Centres is well described by Brendan Delaney and colleagues (page 719) - implementing their vision of collaboration, integration, and translation might hold one of the keys to ensuring that the impending health reforms in the UK do not de-stabilise the system.

\section{Roger Jones \\ Editor}

\section{REFERENCES}

1. Whittaker W, Sutton M, Maxwell M, et al. Predicting which people with psychosocial distress are at risk of becoming dependent on state benefits: analysis of routinely available data. $B M J 2010 ; 341: c 3838$.

2. Dale J, Lang H, Roberts JA, et al. Cost effectiveness of treating primary care patients in accident and emergency: a comparison between general practitioners, senior house officers, and registrars. $B M J$ 1996; 312(7042): 1340-1344.

DOI: 10.3399/bjgp10X515638

C) British Journal of General Practice 2010; 60: 713-792. 